\title{
Pharmacological and immunological effects of praziquantel against Schistosoma japonicum: a scoping review of experimental studies
}

\author{
Shu-Hua Xiao ${ }^{1 *}$, Jun Sun ${ }^{2}$ and Ming-Gang Chen ${ }^{1}$
}

\begin{abstract}
Background: Chemotherapy for schistosomiasis has been around for 100 years. During the past century, great efforts have been made to develop new antischistosomal drugs from antimonials to nonantimonials, and some of these have been used extensively in clinical treatment. With the exception of a few drugs, such as oxamniquine and metrifonate, most of the antischistosomals developed in the pre-praziquantel period have variable limitations with respect to safety and efficacy. Although oxamniquine and metrifonate have been used for schistosomiasis control, they are only effective against Schistosoma mansoni and S. haematobium, respectively. Currently, praziquantel is the only drug used for treatment of all five species of human schistosomes. In this review, the pharmacological and immunological effects of praziquantel against $S$. japonicum are summarized and discussed.

Main text: From the end of the 1970s until the 2000s, scientists have conducted a series of experimental studies on the effects of praziquantel against S. japonicum. These have included examining its unique pharmacological action on schistosomes, the characteristics in susceptibility of the different developmental stages of schistosomes to the drug, the relationship between plasma concentration of the drug and efficacy, the impact of host factors on cidal action of the drug, prevention and early treatment of schistosomal infection, as well as praziquantel-resistant schistosomiasis.

Conclusion: The effects of praziquantel against S. japonicum, as elucidated by the experimental studies that are reviewed in this paper, may have some reference significance for the development of new antischistosomals.
\end{abstract}

Keywords: Praziquantel, Pharmacological action, Immunological action, Schistosoma japonicum, Experimental study, Review

\section{Multilingual abstacts}

Please see Additional file 1 for translations of the abstract into the five official working languages of the United Nations.

\section{Background}

Five species of schistosomes, i.e., Schistosoma japonicum, S. haematobium, S. mansoni, S. intercalatum, and $S$. mekongi, are the major species that can infect humans.

\footnotetext{
* Correspondence: shxiao4@hotmail.com

${ }^{1}$ National Institute of Parasitic Diseases, Chinese Center for Disease Control and Prevention, Key Laboratory of Parasite and Vector Biology, Ministry of Health, WHO Collaborating Centre for Tropical Diseases, Shanghai 200025, People's Republic of China

Full list of author information is available at the end of the article
}

Despite scientists recognizing the symptoms of schistosomiasis earlier than the discovery of its pathogen [1], real chemotherapy was undertaken at a much later stage.

Globally, the era of chemotherapy to treat schistosomiasis began when a human case with $S$. haematobium infection was successfully treated in 1918 with potassium antimony tartrate (PAT) [2]. Since then, many different categories of antischistosomal drugs have been developed, and some of them, including sodium antimony subgallate (Sb-273), lucanthone, hycanthone, amoscanate, metrifonate, oxamniquine, niridazole, furapromidum, and hexachloroparaxylene have been used extensively in the treatment of schistosomiasis [3-8]. With the exception of a few drugs, such as oxamniquine and metrifonate, most of the antischistosomals 
developed in the pre-praziquantel period have variable limitations with respect to safety and efficacy. Moreover, oxamniquine and metrifonate are only effective against S. mansoni and S. haematobium, respectively.

Since the discovery of praziquantel at the end of the 1970s, great progress in schistosomiasis control has been achieved worldwide. This is due to its good levels of tolerance and safety, excellent acceptability by patients, easy administration at a single-dose or very short treatment course (1-2 days), good efficacy profile against all schistosomes parasitizing humans [4-6, 9-11], and low cost $[5,12]$.

Currently, schistosomiasis is distributed in 78 countries in Africa, Asia, and South America. It is estimated that 779 million people live in endemic areas and about 280 million people are infected with schistosomes [13]. In 2006, the strategy for schistosomiasis control proposed by the World Health Organization was to reduce disease burden, i.e., periodic treatment of at-risk populations with praziquantel (preventive chemotherapy), which aimed to cure mild symptoms and prevent infected people from developing severe, late-stage chronic disease [14-16]. Even though re-infection may occur after treatment, as praziquantel is only effective against the very early stage of juvenile (three-hour old worm, day 0 schistosomula) and adult worms but has little effect against young developing stages of the parasites [17-19], the risk of developing severe disease is diminished and even reversed when treatment is started early in life [14].

Since the end of the 1970s until the 2000s, scientists have conducted a series of experimental studies on the effects of praziquantel against S. japonicum. These have included examining its unique pharmacological action on schistosomes, the characteristics in susceptibility of different developmental stages of schistosomes to the drug, the relationship between plasma concentration of the drug and efficacy, the impact of host factors on cidal action of the drug, prevention and early treatment of schistosomiasis, as well as praziquantel-resistant schistosomiasis. In this review, relevant data on these studies are summarized.

\section{Unique pharmacological effects of praziquantel against schistosomes}

Praziquantel has three unique pharmacological effects on S. japonicum and S. mansoni, i.e., stimulation of worm motor activity, spasmodic contraction of the musculature, and vesicle formation in tegument [20-25]. The former two actions link the subsequent hepatic shift of the worms in vivo, while the latter is key to kill the worm.

\section{Stimulation of worm motor activity and spasmodic contraction of musculature}

The minimal effective concentrations (MECs) of praziquantel required to induce increased motor activity followed by contraction of various developmental stages of $S$. mansoni and $S$. japonicum in vitro are similar, i.e., $0.005-0.1 \mu \mathrm{g} / \mathrm{ml}$ and $0.005-0.05 \mu \mathrm{g} / \mathrm{ml}$, respectively (see Table 1). With these MECs of praziquantel, the increased activity of parasites occurs almost immediately and the contraction of the worm musculature typically begins after a short lag phase. At a higher concentration of 1 or $10 \mu \mathrm{g} / \mathrm{ml}$, marked contraction and paralysis masks the early stimulation phase $[25,26]$. Praziquantel-induced stimulation of motor activity of adult $S$. japonicum worms is similar to the effect of serotonin (5-HT) on the worms in many aspects. However, praziquantel neither increases the endogenous 5-HT of schistosomes nor enhances uptake of exogenous 5-HT of the worm. Praziquantel likely displays 5-HT-like action or is a 5-HT receptor agonist [23, 27].

Based on in vitro analyses using some neurotransmitters or various compounds known to interact with the schistosome's neuroreceptive sites and relevant blocking agents, it is suggested that the spasmodic contraction of S. mansoni and S. japonicum induced by praziquantel does not happen through neurotransmitters [20, 24, 28]. Nevertheless, praziquantel causes a rapid rise in the tension of the musculature of male $S$. mansoni worms, which is related to the muscle cell membrane potential. The resting membrane potential (RMP) of a male worm's muscle cell is $-30.7 \pm 1.2 \mathrm{mV}$, but in the depolarization induced rapidly by praziquantel the RMP rises to $15.6 \pm 3.1 \mathrm{mV}$. Since in the incubation medium without sodium ions $\left(\mathrm{Na}^{+}\right)$, low concentration of calcium ion $\left(\mathrm{Ca}^{2+}\right)$, or high concentration of magnesium ions $\left(\mathrm{Mg}^{2+}\right)$, the contractile activity of worm musculature caused by praziquantel is blocked, the action of the drug on RMP of the worm's muscle cells might be related to an increase in the tension of the parasite's musculature $[29,30]$.

Microelectrode studies have indicated that the membrane potentials of male schistosomes are derived from these sources i.e., tegument membrane, muscle masses, and the basal lamina, interstitial fibers, and extracellular space surrounding the muscle. Further studies found that the rise of tegumental membrane RMP and muscle RMP caused by praziquantel was slow. Hence, it seems that praziquantel-induced contraction of schistosomes is not dependent on changes in the membrane potential [31, 32].

According to in vivo studies, these two pharmacological activities are related to the hepatic shift of schistosomes induced by praziquantel $[25,33]$. The hepatic shift of schistosomes caused by praziquantel in vivo is so fast that 5 min after $S$. japonicum-infected mice are orally administered with praziquantel at a single curative dose of $300 \mathrm{mg} / \mathrm{kg}, 94.6 \%$ of the worms have been found to shift to the liver [34]. Meanwhile, other antischistosomal drugs, 
Table 1 The minimal effective concentrations (MECs) of praziquantel needed to induce an increased in motor activity, contraction of musculature or vesicle formation in different developmental stages of S. mansoni and S. japonicum

\begin{tabular}{|c|c|c|c|c|c|}
\hline \multirow[t]{2}{*}{ Stage } & \multicolumn{3}{|c|}{ MEC $(\mu \mathrm{g} / \mathrm{ml})$ producing } & \multirow{2}{*}{$\begin{array}{l}\text { Time of onset } \\
\text { of vesiculation }\end{array}$} & \multirow[t]{2}{*}{ Vesicle number } \\
\hline & Stimulation & Contraction & Vesiculation $^{a}$ & & \\
\hline S. mansoni & \multicolumn{3}{|l|}{ Reference [26] } & & \\
\hline Day 0 & 0.005 & 0.010 & 0.1 & $2-4 \mathrm{~h}$ & Few \\
\hline Day 3 & 0.010 & 0.010 & 1.0 & $>4 h$ & Few \\
\hline Day 7 & 0.010 & 0.010 & 1.0 & $>4 h$ & Few \\
\hline Day 14 & 0.010 & 0.010 & 0.1 & $30 \mathrm{~min}$ & Many \\
\hline Day 28 & 0.005 & 0.010 & 0.1 & $30 \mathrm{~min}$ & Many \\
\hline Day 35 & 0.005 & 0.010 & 0.1 & 5-15 min & Very many \\
\hline Day 42 & 0.005 & 0.010 & 0.1 & 5-15 min & Very many \\
\hline S. japonicum & \multicolumn{3}{|l|}{ Reference [41] } & & \\
\hline Day 0 & 0.01 & 0.05 & 0.5 & $3-4 h$ & Few \\
\hline Day 3 & 0.01 & 0.05 & 1.0 & $24 \mathrm{~h}$ & Very few \\
\hline Day 7 & 0.01 & 0.05 & 1.0 & $24 \mathrm{~h}$ & Very few \\
\hline Day 14 & 0.01 & 0.05 & 1.0 & $2 \mathrm{~h}$ & Many \\
\hline Day 21 & 0.01 & 0.05 & 0.1 & $2 \mathrm{~h}$ & Many \\
\hline Day 28 & 0.005 & 0.05 & 0.1 & $2 \mathrm{~h}$ & Many \\
\hline Day 35 & 0.005 & 0.05 & 0.1 & $15 \mathrm{~min}$ & Very many \\
\hline Day 42 & 0.005 & 0.05 & 0.1 & $15 \mathrm{~min}$ & Very many \\
\hline
\end{tabular}

abserved by light microscopy

${ }^{\mathrm{b}} \mathrm{Few} \leq 5$ vesicle per parasite, many $=5-20$ vesicles per parasite, and very many $\geq 20$ vesicles per parasite

such as PAT, furapromidum, artemether, oxamniquine, mefloquine, and various ozonides such as OZ78, and OZ418 (synthetic 1,2,4-trioxolanes, secondary ozonides, or OZs) showed slower action in S. japonicum or S. mansoni infections with respect to hepatic shift or tegumental damage [35-40].

Vesicle formation in the tegument of Schistosoma worms Vesicle formation in the tegument of Schistosoma worms is one of the earliest and most important effects of praziquantel. It is probably correlated to subsequently killing the parasites and is also consistent with susceptibilities of various developmental stages of schistosomes to the drug. It has been shown through light microscopy (LM) that the immature developmental stages (3-, 7-, and 14-day-old S. mansoni and S. japonicum worms) are particularly resistant (see Table 1) [26, 41]. Scanning electron microscopy (SEM) has been used to observe tegument of various stages of schistosomula exposed to praziquantel and revealed that a concentration of $30 \mu \mathrm{g} / \mathrm{ml}$ insulted the tegument of day 0 schistosomula (skin stage) where swelling, fusion, and vesicle formation were recorded. However, day 3, day 7, and day 14 juvenile worms exhibited no or only slight tegument damage. Apparent damage to the tegument of day 21 schistosomula and day 28 , day 35 , and day 42 adult worms was seen 15 min after exposure to the same concentration of praziquantel that resulted in severe damage to the tegument, as was revealed 4-24 h later [19, 42]. All three aforementioned praziquantel-induced pharmacological effects have also been described for S. mansoni worms [43].

\section{Praziquantel-induced damage of developmental stages of} S. japonicum worms and host cellular response

Examination of day 0, day 21, day 28, day 35, and day 42 schistosomes $0.5-24 \mathrm{~h}$ after oral administration of praziquantel $(400 \mathrm{mg} / \mathrm{kg})$ has revealed extensive vesiculation and rupture of the tegument, while little or only mild and local vesiculation was seen in the tegument of day 3 , day 7, day 11, and day 14 schistosomula. Moreover, strong host cell response was found around damaged day 0 and adult schistosomes (see Table 2) [44]. Meanwhile, after praziquantel administration, alkaline phosphatase (AKP) activity and glycogen content in day 0 schistosomula has been shown to decrease significantly or even disappear, while in day 3 and day 7 schistosomula only a few showed a mild change in both AKP activity and glycogen content [45]. Four hours after administration of praziquantel using the same dose and route, observation using SEM revealed no apparent tegumental damage in day 3 , day 7 , and day 14 schistosomula, while slight or moderate tegument damage was detected in day 21 worms. On the contrary, severe tegument damage was observed in adult schistosomes $[19,42]$. 
Table 2 Praziquantel-induced damage on tegument in different developmental stages of S. japonicum, harbouring in mice, and treated orally with the drug at a single dose of $400 \mathrm{mg} / \mathrm{kg}$ for $0.5-24$ hours $^{\mathrm{a}}$

\begin{tabular}{|c|c|c|c|c|}
\hline \multirow{2}{*}{$\begin{array}{l}\text { Developmental stages } \\
\text { of schistosomes (d) }\end{array}$} & \multicolumn{2}{|c|}{ Percentages of worm tegument showing damage ${ }^{b}$} & \multicolumn{2}{|c|}{ Host cell response expressed by dominant leukocytes ${ }^{c}$} \\
\hline & Vesiculation & Rupture & Neutrophils & Lymphocytes \\
\hline $\mathrm{d} 0$ & 41.8 & 49.2 & $47.5 \pm 8.2$ & \\
\hline $\mathrm{d} 21, \mathrm{~d} 28, \mathrm{~d} 35, \mathrm{~d} 42$ & $20.4-38.7$ & $17.9-56.2$ & $26.8 \pm 5.2-58.4 \pm 12.2^{d}$ & \\
\hline$d 3, d 11, d 14$ & \multicolumn{2}{|c|}{ Normal tegument in most worms, or emergence of very few vesicles } & & $12.8 \pm 5.9-16.8 \pm 5.0$ \\
\hline d7 & \multicolumn{2}{|l|}{ Ditto } & & $2.5 \pm 0.7$ \\
\hline
\end{tabular}

a Data from reference [44]

${ }^{b} 2-3$ mice harbouring different developmental stages of schistosomes killed $0.5,1,4$ and $24 \mathrm{hr}$ after treatment, skins (d0), lungs (d3) or livers (d11, d14, d21, d28, $\mathrm{d} 35, \mathrm{~d} 42$ ) removed for routine preparation of tissue section

'Each value represents $40-80$ sections

${ }^{\mathrm{d}}$ The cells around the $\mathrm{d} 21$ schistosomules mainly lymphocytes

The results suggest that the lower efficacy of praziquantel in day 21 schistosomula might be attributed to the low level of antischistosome antibody present in the host 3 weeks after infection. Further observation of mice infected with cercariae for 21 days and treated orally with praziquantel at a higher daily dose of $500 \mathrm{mg} / \mathrm{kg}$ for $1-3$ days revealed worm reduction rates of 43.8-90.4\% [46]. Examination using SEM showed that under treatment with the higher daily dose of praziquantel for 3 days, day 21 schistosomula had severe swelling, erosion, and peeling of the tegument, accompanied by the attachment of the host leukocytes on the worm's surface. This demonstrates that, if given at a higher daily dose for 3 days, praziquantel can directly kill day 21 schistosomula [47].

\section{Recovery of different developmental stages of schistosomes after exposure to praziquantel}

Examination using LM has indicated that S. japonicum at different developmental stages exposed to a praziquantel dose of $30 \mu \mathrm{g} / \mathrm{ml}$ for $15 \mathrm{~min}$ and then transferred to a drug-free medium for another $24 \mathrm{~h}$ results in a spasmodic contracted worm body that was elongated with normal motor activity on day 0 , day 3 , day 7 , day 14 , day 21 , and day 28 . In day 35 and day 42 adult worms, relaxation of contracted musculature was also seen, but numerous vesicles were still observed in the tegument. If the exposure period was extended to 4 h, day 3 , day 7 , day 14 , and day 21 schistosomula recovered completely, while day 35 , day 42 , and some day 0 and day 28 worms still revealed abnormalities [41]. Similar results were obtained by SEM examination, except that a few day 21 schistosomula had severe tegumental injury [42]. Stage-specific difference also occurred in S. mansoni worms [26].

\section{Stage-specific susceptibility of $S$. japonicum worms to praziquantel and exposure of worm surface antigen} Praziquantel has no apparent therapeutic effect in mice infected with day 3-day $21 \mathrm{~S}$. japonicum schistosomula, but it does have an effect on day 0 schistosomula and day 28-day 42 adult schistosomes [17, 19]. Observation using transmission electron microscopy (TEM) and SEM has indicated that 5-30 min after exposure of adult $S$. japonicum worms to praziquantel in vitro or in vivo, the tegument of the worm showed extensive damage, including emergence of numerous ball-like structures or bulbs in the ridges, swelling and rupture of cytoplasmic processes, destruction of the nuclei of the syncytium, decrease in tegumental AKP, and erosion and peeling of the tegumental surface, followed by the attachment of host leukocytes to the denuded surface [48-52].

It has been demonstrated that adult schistosomes may acquire the molecules of host origin (host antigens) that incorporated into their surface, which results in the evasion of host immune reaction [53]. Since praziquantel is able to quickly damage the tegument of schistosomes, exposure of worm surface antigen will follow. Ten to $30 \mathrm{~min}$ after administration of praziquantel at a dose of $300 \mathrm{mg} / \mathrm{kg}$ given to adult $S$. japonicum-infected mice and using the indirect fluorescent antibody technique (IFAT), exposure of worm surface antigen extended gradually to $1 / 3-1 / 2$ of the worm's surface in $6 \mathrm{~h}$. The speed, degree, and extent of antigen exposure in schistosomes coincides with the tegument alteration, as observed by SEM, and these are dose-dependent [23, 50, 54]. Further examination using the IFAT indicated that $4 \mathrm{~h}$ after oral administration of praziquantel at a dose of $400 \mathrm{mg} / \mathrm{kg}$ given to mice infected with various developmental stages of S. japonicum, the percentage of exposure of worm surface antigen in day 0 , day 3-day 14, day 21 , day 28 , and day 42 were $89.8 \%, 0-10 \%, 32.9 \%, 25.7 \%$, and $41.7 \%$, respectively; $16 \mathrm{~h}$ later, over $50 \%$ of the adult worms isolated from liver tissue showed exposure of worm surface antigen $[19,54,55]$. These results suggest that the susceptibility of different developmental stages of S. japonicum to praziquantel is correlated with the exposure of worm surface antigen. 


\section{Uptake of $\left[{ }^{3} \mathrm{H}\right]$ praziquantel by different developmental stages of schistosomes}

It has been shown that when adult schistosome-infected mice are treated orally with $\left[{ }^{3} \mathrm{H}\right]$ praziquantel, the radioactivity levels of the worms reach a maximum $0.5-1 \mathrm{~h}$ after administration, and then decline markedly $4 \mathrm{~h}$ later. In vitro, the uptake of $\left[{ }^{3} \mathrm{H}\right]$ praziquantel by bisexual worms has also been shown to be prompt and increase with the concentration of the drug. After these worms were transferred to a drug-free medium for $15 \mathrm{~min}$, radioactivity decreased by $71-80 \%$, indicating that $\left[{ }^{3} \mathrm{H}\right]$ praziquantel enters into the worms by a simple diffusion mechanism. This is also confirmed by determining the amount of praziquantel using high performance liquid chromatography [56-58].

In a further study, mice infected with various stages of schistosomes were treated orally with $\left[{ }^{3} \mathrm{H}\right]$ praziquantel. Thirty minutes to four hours after treatment, the amount of the silver particles detected in tissues of day 0 worms was significantly lower than the corresponding groups of schistosomes of other stages. This suggests that the susceptibility of different developmental stages of schistosomes to praziquantel is not necessarily related to the amount of praziquantel taken by the worms [59].

\section{Praziquantel-induced muscular and tegumental effects on schistosomes are $\mathrm{Ca}^{2+}$ dependent} $\mathrm{Ca}^{2+}$ influx induced by praziquantel

In vitro studies have demonstrated that spasmodic contraction of S. mansoni and S. japonicum worms depends on the existence of $\mathrm{Ca}^{2+}$, and is inhibited by high concentrations of extracellular $\mathrm{Mg}^{2+}$. The rapid contractile activity of male S. mansoni worms induced by praziquantel has been explained by the change in the permeability of the parasite to $\mathrm{Ca}^{2+}$, which results in an increased calcium influx into the worm and an induction of sustained contraction of worm musculatures. Praziquantel also stimulates the influx of $\mathrm{Na}^{+}$, but decreases the influx of potassium ion $\left(\mathrm{K}^{+}\right)[20,24,28,29,60]$.

It has been shown that when adult $S$. mansoni worms maintained in Hanks' balanced salt solution (HBSS) with ${ }^{45} \mathrm{Ca}^{2+}$ for 40 min were transferred to a zero $\mathrm{Ca}^{2+} \mathrm{HBSS}$, a biphasic efflux of ${ }^{45} \mathrm{Ca}^{2+}$ from the parasites was observed, i.e., rapid decrease in the first $2 \mathrm{~min}$, followed by a slower rate in the next $40 \mathrm{~min}$. The amounts of total calcium in worms incubated in HBSS and calcium-free HBSS for $1 \mathrm{~h}$ were $3.9 \pm 0.5$ to $2.7 \pm 0.4 \mathrm{mmol} / \mathrm{kg}$ wet weight, respectively, indicating that about $30 \%$ of a worm's calcium is exchangeable. This exchangeable fraction may play an important role in maintaining the contractile activity of the schistosome [61, 62].

Initially, it has been suggested that vesicle formation induced by praziquantel is independent of the concentration of the external calcium, but subsequent studies have demonstrated that vesicle formation is dependent on the presence of calcium in the external medium [63]. Further studies have shown that when male S. japonicum worms were maintained at $37^{\circ} \mathrm{C}$ in $\mathrm{HBSS}$ with $1.4 \mathrm{mmol} / \mathrm{L}$ of ${ }^{45} \mathrm{Ca}^{2+}$ for 30 min before praziquantel was added, or both the drug and ${ }^{45} \mathrm{Ca}^{2+}$ were added to the medium simultaneously, the ${ }^{45} \mathrm{Ca}^{2+}$ uptake of the worms increased significantly within 1-30 min. Thereafter, accumulation of ${ }^{45} \mathrm{Ca}^{2+}$ in the worms was no longer observed [64]. On the other hand, if worms were exposed to praziquantel at $4{ }^{\circ} \mathrm{C}$ for $2 \mathrm{~h}$, a sustained increase in ${ }^{45} \mathrm{Ca}^{2+}$ content in the worms was observed, but no tegument damage or spasmodic contraction was detected. When worms maintained at $4{ }^{\circ} \mathrm{C}$ during exposure to praziquantel were transferred to $37^{\circ} \mathrm{C}$, a strong spasmodic contraction occurred and numerous vesicles appeared on the tegumental surface within 15-30 min. Thus, temperature appears to be an important factor in inducing contractile activity or the development of vesicles [64, 65].

Further studies have shown that at $37^{\circ} \mathrm{C}$, the percentage of ${ }^{45} \mathrm{Ca}^{2+}$ distributed in the tegumental cytoplasm decreased, while that in the musculature increased, but no change was detected in the total calcium content of a worm. No such phenomenon was observed at $4{ }^{\circ} \mathrm{C}$. Thus movement of calcium between parts of the worm is what may cause praziquantel-induced contraction and tegumental damage, rather than an influx of calcium from the medium [66].

\section{Voltage-gated $\mathrm{Ca}^{2+}$ channels (VGCCs)}

Although praziquantel clearly affects $\mathrm{Ca}^{2+}$ homeostasis in worms, the exact action mechanism is still not known. Kohn et al. [67] have suggested that VGCCs, e.g., heteromultimeric membrane protein complexes consisting of a pore-forming, voltage-sensing $\alpha_{1}$ subunit, may regulate intracellular $\mathrm{Ca}^{2+}$ levels and represent a possible site of action for the drug.

Three high voltage-activated $\mathrm{Ca}^{2+}$ channel $\alpha_{1}$ subunit cDNAs were cloned from S. mansoni. One of these sequences most closely resembles the L-type class of high voltage-activated $\alpha_{1}$ subunits. The other two sequences are most closely related to non L-type $\alpha_{1}$ subunits. The other two $\mathrm{Ca}^{2+}$ channel $\beta$ subunits were also cloned and expressed, one from $S$. mansoni and the other from $S$. japonicum. These two $\beta$ subunits $\left(S m \mathrm{Ca}_{\mathrm{v}} \beta \mathrm{A}\right.$ and $\left.\mathrm{SjCa}_{\mathrm{v}} \beta\right)$ have structural motifs that differ from those found in other known $\beta$ subunits, and co-expression of these with a mammalian $\alpha_{1}$ subunit conferred sensitivity of the latter to praziquantel. The primary site of $\beta$ subunit interaction with $\alpha_{1}$ subunits is the $\beta$ interaction domain (BID). The $\beta$ BIDs of $S m \mathrm{Ca}_{\mathrm{v}} \beta \mathrm{A}$ and $\mathrm{SjCa}_{\mathrm{v}} \beta$ lack two conserved serines that each constitute a consensus site for protein kinase $\mathrm{C}$ phosphorylation, and the absence of 
these serines appears to render schistosome cells sensitive to praziquantel [67-70].

Although several questions remain to be addressed, the hypothesis dealing with the importance of VGCCs as a possible molecular target of praziquantel against schistosomes has been proposed [71]. Voltage-operated $\mathrm{Ca}^{2+}$ channels (VOCCs) mediate an extracellular $\mathrm{Ca}^{2+}$ influx in muscle fibers of $S$. mansoni worms and, along with $\mathrm{Ca}^{2+}$ mobilization of sarcoplasmic reticulum, contribute to muscle contraction [72]. On the other hand, it is known that schistosomes cannot synthesize purine nucleosides de novo, however, in vitro praziquantel may inhibit nucleoside uptake by schistosomes but not by mammalian cells. Adenosine is known to bind to specific receptors and to behave as an indirect antagonist of calcium release in mammalian cells. If calcium channels are correlated with adenosine receptors also in schistosomes, this would support the hypothesis that praziquantelinduced calcium influx may be correlated with an adenosine receptor blockade [73].

There are two contrasting views on whether schistosome VGCCs are involved in the mechanism of action of praziquantel. Valle et al. [74] have indicated that the sequences of cDNAs coding for the $S m C a v \beta 1$ and $S m C a v \beta 2$ subunits of different sensitive and resistant strains have been cloned and expressed, but no meaningful differences were detected. They were also unable to demonstrate major quantitative differences in the expression of the $\beta$ subunits obtained from various strains and various developmental stages of $S$. mansoni worms [74]. In another report, the authors used a unique and indirect way to support this hypothesis. They developed an assay based on the transcriptional response of $S$. mansoni worms to heat shock to confirm that day 42 schistosomes in mice are sensitive to praziquantel, which is not the case for day 28 schistosomes. Meanwhile, this sensitivity develops for day 37-day 40 schistosomes, suggesting that the differential effects of praziquantel on day 28 and day 42 worms are not based on cell exclusion as praziquantel can enter the cells of these two stages of schistosomes [75]. Meanwhile, a species of free-living flatworms (Dugesia japonica) was used to test the hypothesis of the action mechanism of praziquantel. The result provides the first genetic evidence implicating a molecular target crucial for in vivo praziquantel activity and supports the VOCC hypothesis of praziquantel efficacy [76].

In order to test the hypothesis that calcium channels of schistosomes are the targets for the action of praziquantel, adult $S$. mansoni worms were pre-exposed to the calcium channel blockers nicardipine and nifedipine for $1 \mathrm{~h}$ in vitro, followed by adding a praziquantel dose of $3 \mu \mathrm{mol} / \mathrm{L}$, which is supposed to kill the majority of the schistosomes, and continuous incubation overnight.
The worms were then washed and transferred to a drugfree medium for observation for the following 7-10 days. About $50 \%$ of schistosomes survived the praziquantel exposure. Further pre-exposure of schistosomes to the actin depolymerizing agent, cytochalasin $\mathrm{D}$, resulted in the parasites being completely refractory to the effects of very high concentrations of praziquantel of up to $36 \mu \mathrm{mol} / \mathrm{L}$. Similar results were also obtained using adult S. japonicum worms. Meanwhile, examination using SEM showed that there was no or slight damage to the tegument surface and gynecophoral canal of the worms pre-exposed to cytochalasin D or nicardipine and nifedipine, which survived in the critical concentration of praziquantel. All these facts are consistent with the hypothesis that schistosome calcium channels may be involved in the action mechanism of praziquantel [77-79].

In a subsequent study, however, Pica-Mattoccia et al. [80] found that exposure of schistosomes to praziquantel after pre-incubation with cytochalasin D not only allows the complete survival of the parasites, but is accompanied by an even higher calcium uptake. Nicardipine and nifedipine also failed to prevent the calcium influx induced by praziquantel. These results place some doubt on the crucial role of $\mathrm{Ca}^{2+}$ influx in the antischistosomal activity of praziquantel and on the importance of VGCCs, speculated as the possible molecular target of praziquantel against schistosomes [12, 80]. In recent years, nifedipine has been found to be effective against adult and juvenile $S$. mansoni worms in vitro, which is different from praziquantel. Hence, the authors support the idea of $\mathrm{Ca}^{2+}$ subunit as drug targets, but so far no in vivo data are available [81].

\section{Relationship between efficacy and plasma concentration of praziquantel}

It is generally believed that the toxicity and efficacy of drugs are often closely related to their concentration in the host's blood. Praziquantel is best absorbed from the duodenum and ileum, relatively well from the rectum, and much less so from the colon or stomach. When praziquantel has been injected into various segments of alimentary canal of rabbits infected with S. japonicum, the hepatic shift of schistosomes was best from duodenal administration and worst from colon and stomach injection [82].

Adult S. japonicum worms lodge in the vessels of the portal vein system, but the relationship between blood concentration and efficacy of praziquantel is unclear (see Table 3). In both mice and rabbits infected with schistosomes for 4 weeks and treated orally with praziquantel at a single dose of $300 \mathrm{mg} / \mathrm{kg}$ (mice) or $40 \mathrm{mg} / \mathrm{kg}$ (rabbits), the worm reduction rates were similar; in mice the peak concentration of praziquantel in peripheral plasma was $20.2 \mu \mathrm{g} / \mathrm{ml}$ and in rabbits it was only $0.05 \mu \mathrm{g} / \mathrm{ml}$. 
Table 3 Pharmacokinetics and therapeutic efficacy of praziquantel in S. japonicum-infected mice and rabbits after oral (PO), rectal (PR) and intramuscular (IM) administration

\begin{tabular}{|c|c|c|c|c|c|c|c|c|c|}
\hline Animal & Time after infection (week) & Dose (mg/kg) & Route & $\operatorname{Tmax}(h)$ & Cmax $(\mu \mathrm{g} / \mathrm{ml})$ & $T_{1 / 2}(h)$ & $A \cup C_{0-\infty}(\mu \mathrm{g} / \mathrm{ml} \times \mathrm{h})$ & Worm burden reduction (\%) & Reference \\
\hline \multirow[t]{4}{*}{ Mice } & 4 & 300 & $\mathrm{PO}$ & 0.27 & 20.2 & 0.8 & 30.6 & 46.2 & \\
\hline & 5 & 300 & $\mathrm{PO}$ & 0.59 & 29.1 & 0.5 & 49.8 & 65.3 & \\
\hline & 5 & 150 & $\mathrm{IM}$ & 0.58 & 31.3 & 0.7 & 60.3 & 52.2 & \\
\hline & 6 & 300 & $\mathrm{PO}$ & 0.50 & 34.0 & 0.6 & 55.2 & 93.8 & \\
\hline \multirow[t]{9}{*}{ Rabbits } & 4 & 40 & $\mathrm{PO}$ & 0.3 & 0.05 & 0.9 & 0.08 & 60.8 & \\
\hline & 8 & 40 & $\mathrm{PO}$ & 0.34 & 0.64 & 3.04 & 3.03 & 94.9 & \\
\hline & 12 & 40 & $\mathrm{PO}$ & 0.43 & 0.50 & 1.08 & 1.01 & 89.0 & \\
\hline & 4 & 20 & $\mathrm{IM}$ & 1.49 & 1.92 & 1.27 & 8.17 & 70.9 & \\
\hline & 8 & 20 & IM & 1.32 & 1.65 & 1.86 & 7.59 & 88.0 & \\
\hline & 12 & 20 & IM & 1.11 & 1.45 & 1.35 & 5.25 & 95.2 & [83] \\
\hline & 8 & 40 & $\mathrm{PO}$ & $0.5-0.6$ & $0.1-0.3$ & $1.3-1.6$ & $0.1-0.9$ & 72.5 & \\
\hline & 8 & 40 & PR & 0.4 & $0.7-0.8$ & $0.5-0.6$ & $0.9-1.0$ & 90.1 & \\
\hline & 8 & 20 & $\mid \mathrm{M}$ & $0.5-1.2$ & $0.8-2.3$ & $1.2-1.6$ & $2.6-5.9$ & 92.2 & [84] \\
\hline
\end{tabular}

When praziquantel $(40 \mathrm{mg} / \mathrm{kg})$ was injected into the duodenum of rabbits infected with schistosomes for four or 8 weeks, higher praziquantel concentrations of $16-19 \mu \mathrm{g} /$ $\mathrm{ml}$ were detected in the plasma of the portal vein $15 \mathrm{~min}$ after administration. In the subsequent $0.5-8 \mathrm{~h}$, drug concentrations declined from 9 to $15 \mu \mathrm{g} / \mathrm{ml}$ to $0.6-1.3 \mu \mathrm{g} / \mathrm{ml}$, while those in the femoral vein 5-15 min after administration were as low as $0-0.22 \mu \mathrm{g} / \mathrm{ml}$ and $0.13-0.56 \mu \mathrm{g} / \mathrm{ml}$ [83]. The results demonstrate that praziquantel is extensively metabolized in the first pass through the liver. When aforementioned schistosome-infected rabbits were intramuscularly injected with praziquantel at a dose of $20 \mathrm{mg} / \mathrm{kg}$, the efficacy was similar to when the drug was given orally at a single dose of $40 \mathrm{mg} / \mathrm{kg}$. Interestingly, 5 min to $4 \mathrm{~h}$ after intramuscular administration, the plasma concentrations of praziquantel in portal vein blood and femoral vein blood were $1.2-2 \mu \mathrm{g} / \mathrm{ml}$ and $0.6-2.9 \mu \mathrm{g} / \mathrm{ml}$, respectively, and then declined to $0.6-0.9 \mu \mathrm{g} / \mathrm{ml} 8 \mathrm{~h}$ later [84]. It was found that in the worm pairs exposed to low concentrations of praziquantel $(0.1-1 \mu \mathrm{g} / \mathrm{ml})$ for $8 \mathrm{~h}$ and which were then transferred to a drug-free medium for continuous incubation, their motor activity recovered to norma1 $24 \mathrm{~h}$ later. If the worm pairs were exposed to praziquantel at a higher concentration of $10 \mu \mathrm{g} / \mathrm{ml}$ for various intervals within $24 \mathrm{~h}$, the worms could not recover their normal activity, resulting in male and female worms dying 6-7 days after incubation.

The same is true in in vivo studies, e.g., in bisexual schistosomes collected from $S$. japonicum-infected mice treated orally with praziquantel at a lower single dose of $100 \mathrm{mg} / \mathrm{kg}$ at various intervals within $72 \mathrm{~h}$ and incubated in a drug-free medium for 3 days, most of the worms could recover to normal activity. If bisexual worms were collected from the infected mice treated with praziquantel at a higher single oral dose of $500 \mathrm{mg} / \mathrm{kg}$ for $8-72 \mathrm{~h}$, most of the bisexual worms failed to return to normal activity [25]. In another study, three groups of rabbits infected with $S$. japonicum for 8 weeks were treated with a single dose of praziquantel by oral $(40 \mathrm{mg} / \mathrm{kg})$, rectal $(40 \mathrm{mg} / \mathrm{kg})$, or intramuscular $(20 \mathrm{mg} / \mathrm{kg})$ administration. Although the dosage of praziquantel administered intramuscularly was only half that given orally or rectally, the maximum plasma concentration $(\mathrm{Cmax})$ and the area under the concentration-time course curve (AUC) of praziquantel after intramuscular administration was 5-10-fold higher than after oral or rectal administration. Nevertheless, the therapeutic effect of intramuscular administration was not greater than that achieved by rectal administration. On the other hand, the Cmax and AUC in those that were administered rectally were slightly higher than those administered orally, however, the therapeutic effects of these two groups were similar (see Table 3). Furthermore, after praziquantel was administered to schistosome-infected rabbits via the intraduodenal or intramuscular route, the pattern of the drug distributed in the plasma of portal vein and femoral vein was similar to those mentioned above. Meanwhile if the drug was administered rectally, the tendency of praziquantel distributed in the plasma of portal vein and femoral vein was similar to that shown in those that were administered via the intraduodenal route [84].

All these results indicate that no direct correlation exists between route of administration, or between levels of praziquantel in peripheral or portal venous blood, and therapeutic effect $[83,84]$. The results confirm the importance of the time the parasite is exposed to the drug $[43,85]$.

\section{Efficacy of praziquantel is dependent on host immune responses}

It has been known that many antischistosomal drugs, including praziquantel, are dependent on host immune 
status and immune effector mechanisms, particularly antibodies. Many experimental studies have been carried out in $S$. mansoni-infected mice immunosuppressed by T-cell deprivation or B-cell depleted mice, and the results have been fully summarized in several reviews [86-89]. Here, we describe only the data dealing with the role of host immune response during exposure of $S$. japonicum to praziquantel either in vivo or in several immune systems in vitro.

\section{Adult schistosomes}

When male schistosomes were maintained in a culture medium containing immune rabbit serum (IRS) and a praziquantel concentration of 1 or $30 \mu \mathrm{g} / \mathrm{ml}$, a granular flocculent material appeared on the drug-damaged surface of the worms. This flocculent material aggregated to form a membrane-like sheath around the worm that accentuated tegumental injury. If IRS was replaced by normal rabbit serum (NRS), no such phenomenon was observed. In terms of male worms exposed to a praziquantel dose of $1 \mu \mathrm{g} / \mathrm{ml}$ for $4 \mathrm{~h}$ and then transferred to a drug-free medium containing IRS, most schistosomes recovered. When male worms were exposed to praziquantel at a higher concentration of $30 \mu \mathrm{g} / \mathrm{ml}$ for one or $4 \mathrm{~h}$ before being transferred to a medium containing NRS, the damaged tegument was repaired and worm activity returned to normal in one half of the worms tested. When IRS replaced NRS, most of the worms did not recover. When male, perfused out from infected mice 1-8 $\mathrm{h}$ after treatment with praziquantel (single oral dose of $50 \mathrm{mg} / \mathrm{kg}$ ) were transferred to a medium containing NRS or IRS and incubated for another 3 days, all or most of the damaged worms recovered to normal. In the worms obtained from infected mice treated with praziquantel at a higher dose of $400 \mathrm{mg} / \mathrm{kg}$ for $4-8 \mathrm{~h}$ and then transferred to a medium containing IRS, neither apparent recovery of tegumental damage nor worm activity were detected. Regarding the worms transferred to the medium containing NRS, some of the worms recovered, at different degrees [90].

Furthermore, for bisexual schistosomes maintained in a medium containing IRS or rabbit antisera to frozen-thawed tegument exudates of adult worms (ASE), glycogenactivated mouse peritoneal neutrophils and complement were exposed to a praziquantel dose of $1 \mu \mathrm{g} / \mathrm{ml}$ for $2-20 \mathrm{~h}$, neutrophils, mediated by the aforementioned membranelike sheath were found attached to the worm's surface. If male and female worms were first exposed to a praziquantel concentration of $30 \mu \mathrm{g} / \mathrm{ml}$ for $1-4 \mathrm{~h}$, then placed in the above medium without the drug, neutrophils were also observed to attach to the damaged tegumental surface of the worms. Attachment of the neutrophils appeared to accentuate tegumental damage, which resulted in worm death within $24 \mathrm{~h}$. No such phenomenon was observed when the immune serum was replaced by NRS [91]. Furthermore, if a Boyden chamber was used, an increase in neutrophil chemotactic activity, induced by praziquanteldamaged worms, was detected [92]. Half an hour after administering a praziquantel dose of $300 \mathrm{mg} / \mathrm{kg}$ to infected mice, the tegument of schistosomes showed swelling and vacuolization at various degrees, followed by a rupture of vacuoles and formation of flocculus materials that attached to the damaged surface of the worms, similar to that seen in schistosomes maintained in the medium containing immune serum and praziquantel. Six hours after medication, numerous polymorphonuclear leukocytes attached to the damaged tegument of the worms and penetrated into the worm's body $12 \mathrm{~h}$ later. Meanwhile, the appearance of pathological changes of the worm tegument caused by praziquantel was seen earlier in male worms than in female worms. Nevertheless, 12-16 h after medication, female worms also had severe damage on the tegument, especially on the surface along the ovary and vitelline glands, which is similar to that observed in in vitro studies. Twenty-four hours after medication, male and female worms died [91, 93]. Similar results were obtained for $S$. mansoni-infected mice treated with praziquantel [43].

These findings indicate that antibodies might play an important role in praziquantel-mediated tegumental damage. In vitro, schistosomes exposed to a praziquantel dose of $10 \mu \mathrm{g} / \mathrm{ml}$ might survive for 1-3 days, and the survival time of female worms is even longer than that of males. While in in vivo studies the elimination of praziquantel from the host and worms has been shown to be rapid [23, 25, 57, 94], tegumental damage of the worms persists after praziquantel treatment, indicating that host factor could sustain praziquantel-induced damage in vivo. As a result of exposure of worm surface antigens, $S$. japonicum seems to be more susceptible to a host-mediated immune attack [23, 54].

Various experimental studies have confirmed that the immune level of the host impacts the efficacy of praziquantel. For example, a single dose of $40 \mathrm{mg} / \mathrm{kg}$ administered to rabbits infected with 3-, 4-, 8-, or 10-week-old $S$. japonicum resulted in worm burden reductions of $14 \%, 46 \%, 84 \%$, and $88 \%$, respectively [95]. Further studies have shown that in rabbits infected with 50, 200, and $400 S$. japonicum cercariae for four and 8 weeks, and receiving the same single oral praziquantel dose of $40 \mathrm{mg} / \mathrm{kg}$, the worm reduction rates of the 8 -week groups were $88 \%, 92 \%$, and $97 \%$, respectively. Similar results were obtained for mice infected with $S$. japonicum and the antibody level was shown to be positively correlated with duration and intensity of the infection $[95,96]$.

\section{Day 0 worms}

In a mouse model, a single oral praziquantel dose of $400 \mathrm{mg} / \mathrm{kg}$ or $600 \mathrm{mg} / \mathrm{kg}$ has a noticeable effect on day 
0 schistosomula (skin stage), but has less of an effect or is even ineffective on 6-48-h-old (skin stage) and day 3 (lung stage) schistosomula. In vitro, the same concentration of praziquantel induced similar stimulation of motor activity and spasmodic contraction in day 0 , day 1 (24-h-old), and day 3 schistosomula, while the druginduced tegument damage in day 0 schistosomula was more severe relative to that of day 1 and day 3 schistosomula. Forty-eight hours after infection, a considerable part of day 1 worms still remained in the skin, and a lower susceptibility to praziquantel revealed their intrinsic resistance to praziquantel. Observation using the IFAT showed that the percentages of exposure of surface antigen in day 0 , day 1 , and day 3 schistosomula were $86.4 \%, 55.2 \%$, and $3.9 \%$, respectively. It is suggested that the differences in susceptibility of these early stages of $S$. japonicum to praziquantel may be related to antigenic composition of their respective tegumental surfaces. Furthermore, when these three different aged schistosomula were injected into the peritoneal cavity of a mouse containing neutrophils or macrophages, the worm surface of day 0 worms rapidly attached by either kind of cells, but such phenomenon was not seen in day 1 and day 3 schistosomula. Similar results were also observed in in vitro studies, indicating differences in body surface properties at different worm ages [97, 98].

Furthermore, histological observations showed that after treatment with praziquantel, day 0 schistosomula in the host's skin were infiltrated by inflammatory cells and some of the cells attached to or penetrated into the worm's body; meanwhile, an increase in degranulation and collapse of the mast cells around the worms occurred. This means that host nonspecific immunity may participate in the killing mechanism during treatment, which is confirmed by the fact that praziquantel can increase the nonspecific immunity of mice after their early-stage infection with cercariae [99].

\section{Synergistic effects of schistosome antigen in combination with praziquantel}

In the 1990s, a S. japonicum vaccine combined with praziquantel was used to enhance the killing effect against juvenile and adult schistosomes. Initially, mice were treated orally with praziquantel at a lower dose of $20 \mathrm{mg} / \mathrm{kg}$ in combination with intraperitoneal injection of class $\operatorname{IgG}_{1}$ monoclonal antibodies ISj51 or ISj55 $2 \mathrm{~h}$ before challenge with cercariae. The same treatment regimen was repeated 4 days later. Using this combined treatment, the worm reductions were $45.3 \%$ and $43 \%$, respectively, which were higher or significantly higher than that of each monoclonal antibody or praziquantel alone [100]. Subsequently, mice received an intraperitoneal injection of monoclonal antibody, McAb14 or McAb24, combined with an oral administration of a praziquantel dose of either 20 or $50 \mathrm{mg} / \mathrm{kg} 2 \mathrm{~h}$ before infection with cercariae; this resulted in worm reductions of $45.4 \%$ and $44.2 \%$, respectively, significantly higher than that of $13.9 \%, 31.5 \%$, or $29.8 \%$ obtained for the groups of mice treated with McAb14, McAb24, or praziquantel alone.

Further studies have shown that in mice or rabbits treated with monoclonal antibody SSj14 combined with a low dosage of praziquantel, or SSj14 together with praziquantel and fenofibrate administered $2 \mathrm{~h}$ before challenge with cercariae, synergistic effects were observed [101, 102]. Furthermore, when mice were given an intraperitoneal injection of monoclonal antibody against schistosomula membrane 1 day before challenge with cercariae, followed by an intraperitoneal injection with a praziquantel dose of $200 \mathrm{mg} / \mathrm{kg}$ on day 3 or day 38 after infection, the worm reduction rates were $91.9 \%$ and $96.9 \%$, significantly higher than that of $17.2 \%$ and $84.9 \%$ as obtained from the corresponding group treated with praziquantel alone. This demonstrates the synergistic effect of praziquantel combined with schistosome monoclonal antibody against juvenile and adult schistosomes [103].

In another experiment, mice infected with $S$. japonicum cercariae for 2 days, 14 days, or 35 days were treated orally with praziquantel at a single dose of $150 \mathrm{mg} / \mathrm{kg}$, followed by intravenous injection of IRS against surface membrane antigen of adult S. japonicum via tail vein $30 \mathrm{~min}$ after administration of the drug. The results showed that the immune serum increased the antischistosomal activity of praziquantel against day 2 , day 14, and day 35 worms by $39 \%, 30 \%$, and $47 \%$, respectively. In addition, praziquantel in combination with another two monoclonal antibodies, 3B6 and IC2, also exhibited synergistic effects against adult schistosomes. All these data demonstrate that humoral immunity plays an important role in the schistosomicidal process of praziquantel [104, 105].

Meanwhile, the immunological response, such as the level of lymphocyte response to phytohemagglutinin (PHA) and adult worm antigen, the T-cell helper activity as well as IgM released from the antibody forming cell, in mice infected with $S$. japonicum increased after treatment with praziquantel. On the other hand, the immunosuppressive effects of infected hosts were improved after treatment, which suggests that besides the host immune status and antischistosome antibody, cellular immunity may also be involved and modulated in the lethal mechanism of praziquantel on the schistosomes [106]. It means that the death of schistosomes induced by praziquantel is closely related to the role displayed by the host.

\section{Prevention and early treatment}

Chemoprophylaxis can be roughly defined as protecting the definitive host from the penetration of cercariae into the skin. It is known that S. japonicum cercariae are more susceptible to praziquantel in water than in 
isotonic saline. The MEC of praziquantel required to kill cercariae in water is $0.05 \mu \mathrm{g} / \mathrm{ml}$. Exposure of cercariae to praziquantel results in immediate contraction, followed by an increase in motor activity, release of gland contents, and separation of the tail from the body. Subsequently, the surface of the cercariae is damaged, as indicated by an increased permeability, followed by swelling of the cercarial body. Examination using TEM has shown that the glycocalyx in the outer surface of tegument decreases markedly or even disappears, and hence the cercariae cannot stand the nonisotonic environment water and dies within 2-4 h [107-109]. When cercariae were placed on the skin of mice treated orally with praziquantel 2-4 $\mathrm{h}$ prior, most of the cercariae were killed rapidly on the surface or keratin layer of the skin $[107,110]$. Meanwhile, the cercariae that penetrated into the dermis or hypodermis showed severe damage and were surrounded by inflammatory cells. Further analysis demonstrated that upon administration of tritiated praziquantel to mice, there was no radioactivity in the skin in the following 2-4 $\mathrm{h}$ after; this supported previous findings regarding the effect of praziquantel on cercariae. Eight to $24 \mathrm{~h}$ after medication, the radioactivity excreted from the skin revealed no apparent effect against the parasites. Therefore, praziquantel exhibited a prophylactic effect, e.g., oral administration of praziquantel at a single dose of $400 \mathrm{mg} / \mathrm{kg}$ given to mice $2-4 \mathrm{~h}$ before infection with $S$. japonicum cercariae resulted in worm reduction rates of $88-100 \%$. If the same oral dose of praziquantel was administered to mice $2-4 \mathrm{~h}$ after infection, lower worm reduction rates of $36-84 \%$ were observed [17, 107]. Nevertheless, when a praziquantel dose of $50 \mathrm{mg} / \mathrm{kg}$ was administered intramuscularly to dogs $4 \mathrm{~h}$ before and after infection, the worm reduction rates were $61 \%$ and $44 \%$, respectively. On the other hand, when praziquantel was given at a higher oral or intramuscular dose to rabbits $4 \mathrm{~h}$ before or after challenge with cercariae, poor prophylactic effects were observed [17]. Hence, the window of praziquantel sensitivity for prophylaxis is very narrow, and only confined to mice. Therefore, praziquantel does not have practical significance for prevention of schistosomiasis.

Although praziquantel given at a single curative dose to mice harboring day 21 schistosomula exhibits less efficacy as evaluated by the worm burden reduction, female worms show apparent shrinkage in size, depigmentation of the gut, degeneration of the vitelline glands, atrophy of the ovary, and disappearance of eggs in the uterus. Meanwhile, the oviposition of female worms is inhibited significantly or even ceased during the following 2-3 weeks [111]. Therefore, it is suggested if praziquantel is given once at appropriate intervals several times to the host starting early after infection, the majority or even all the female worms are expected to be killed just after the worms reach maturity and commence egg production.
Among the regimens tested, the most promising one showed that when praziquantel was administered 21 days after infection, followed by repeated dosing at 1-3-week intervals 2-3 times, all mice were free from female worms (especially in the 3-week interval group) [111]. In rabbits infected with cercariae once every week six times or once every other day five times, initial treatment with praziquantel on day 21 after the first infection at a single dose of $40 \mathrm{mg} / \mathrm{kg}$ followed by administration of the same dose at a two-week interval four or two times resulted in promising effects, with female worm reduction rates of $99-100 \%$. Meanwhile, the presence of adult schistosomes in the same host not only increased the effect of praziquantel against day 21 schistosomula, but also had an effect on day 14 schistosomula $[19,112]$. When rabbits were singly infected with cercariae and received the same dose of praziquantel 21 days after infection, followed by repeated dosing at 1-2-week intervals twice, similar results were observed. Meanwhile, the livers of rabbits showed normal or mild changes, and the parameters relevant to acute schistosomiasis were negative as compared to the controls [112]. In rabbits infected with schistosome cercariae once every other day five times, administration of a praziquantel dose of $30 \mathrm{mg} / \mathrm{kg}$ was started 21 days after the first infection, followed by repeated dosing at a two-week interval twice. Histopathological examination showed that the reduction in the number of hepatic granulomas were $76.5-85.5 \%$. Meanwhile, the structure of the hepatic lobules was normal [113], indicating that either the host was protected from the infection or there was a great decrease in the intensity of the infection.

\section{Resistance to praziquantel}

Currently, praziquantel is the only globally available antischistosomal, and heavy reliance on a single drug for schistosomiasis control may promote the spread of drug-resistant parasites. Experiments with mice have revealed the possibility of selecting praziquantel-tolerant strains of $S$. mansoni after repeated administration of subcurative doses of praziquantel [114].

A series of laboratory studies and clinical trials conducted in Egypt and Senegal between 1995 and 2002 have raised considerable concern about the possible tolerance or development of resistance to praziquantel in schistosomes [115-120]. Indeed, S. mansoni isolates with a somewhat reduced praziquantel susceptibility have been identified by several authors [121-123] However, these observations are fortunately of limited clinical significance thus far [12, 124].

It has been speculated that antimicrobial resistance is responsible for the unusually low cure rates in $S$. mansoniinfected patients from Senegal [119]. In Egypt, patients were not completely cured of $S$. mansoni infections even after praziquantel was administered three times, which is 
the most compelling evidence of praziquantel resistance to date $[117,118,121]$.

In China, treatment of schistosomiasis japonica with praziquantel began in 1978. In the early 1990s, experimental studies indicated that in infected mice treated repeatedly with praziquantel at a curative dose, or in mice infected with 14-18-day-old schistosomula or adult worms and treated with praziquantel at various dose schedules, followed by the passage in the intermediate host snails, i.e., Oncomelania hupensis with miracidia hatching from schistosome eggs laid by the residual female worms, the $F_{1}$ and $F_{2}$ progeny of worms were still susceptible to praziquantel $[125,126]$. In recent years, laboratory studies have successfully developed two isolates of S. japonicum (mainland China) resistant to praziquantel through continuous treatment with subcurative doses of praziquantel and a total of eight passages in O. hupensis snails. Meanwhile, not only are the sensitivities of the adult worms of the two isolates significantly lower than those of the isolates never treated with praziquantel, but cercariae and miracidia are also resistant to the drug $[127,128]$. In order to understand and compare the sensitivities of different isolates of $S$. japonicum to praziquantel, $S$. japonicum-shedding snails from marshland and lake regions of Hunan, Hubei, Jiangxi, Anhui, and Jiangsu provinces were used to infect animals with various isolate(s) of cercariae released from the snails in order to determine the ED50 against adult schistosomes 5 weeks later. The results showed that the sensitivities of various isolates of $S$. japonicum to praziquantel are similar without significant differences [129].

From the 1990s to prior to the 2010s, a series of field studies were carried out in endemic villages distributed in six provinces of China, where praziquantel had been used extensively for 10-14 years. The different prevalence rates were found for schistosomiasis: from low $(3.46 \%)$ to high $(8-12 \%)$. The results showed that $S$. japonicum is still highly susceptible to praziquantel. Meanwhile, when praziquantel was administered to patients at a single oral dose of $40 \mathrm{mg} / \mathrm{kg}$, the efficacy of praziquantel in the area with repeated chemotherapy was not significantly different from that in the newly identified endemic foci [130-137].

All these results suggest that in large areas of China, after extensive and repeated use of praziquantel in the treatment of S. japonicum-infected individuals or mass chemotherapy given to persons in highly endemic areas without preliminary screening for about three decades among tens of million person-times in a huge population, no evidence of tolerance or resistance of $S$. japonicum to praziquantel has been found.

Interestingly, when the area in Egypt at which resistant isolates were identified was revisited to examine the current efficacy of the drug using the same treatment protocol after 10 years of therapeutic pressure, sustained efficacy was recorded despite the presence of schistosome isolates with diminished sensitivity to the drug [138].

\section{Conclusions}

In 1918, PAT initiated the era of chemotherapy for schistosomiasis. Various categories of antischistosomal chemicals have been synthesized and developed since then. However, only a few of these have been introduced for clinical trials. After clinical practice for four decades globally, praziquantel has been confirmed as a very effective and almost the only drug of choice for the treatment of human schistosomiasis. Indeed, the discovery of praziquantel is a milestone, and extensive use of the drug has made a great contribution to schistosomiasis control worldwide.

Experimental studies have shown that in vivo effective antischistosomal drugs, such as PAT, amoscante, oxamniquine, niridazole, furapromidum, mefloquine, and artemisinins can cause a hepatic shift and tegumental damage of schistosomes within 1-3 days post oral administration. However, only praziquantel has a similar effect against schistosomes either in vitro or in vivo at a very low concentration and a very rapid onset. Particularly, the damage to the tegument creates the condition and basis for the host to start the process of killing the worms. Therefore, the effects of praziquantel against schistosomes should have some reference significance for the study of new antischistosomal drugs.

Oral administration of praziquantel to S. japonicuminfected animals exhibits no apparent correlation between therapeutic efficacy and drug concentration in peripheral venous blood, but the relationship between the concentration of the drug in the blood of mesenteric vein and portal vein and therapeutic efficacy is more important $[83,84]$. Praziquantel is absorbed mainly from the small intestine [82] and thereafter schistosomes are exposed to it, lose their power to lodge in the superior mesenteric vein and portal vein, and shift back to the liver. As the drug possesses a strong first pass effect in the liver where $>90 \%$ of the drug is metabolized (supported by the low but satisfactory drug level in the peripheral circulation and high blood level in the portal vein), worms distributed in inferior mesenteric veins and its branches are insulted and quickly shift to the liver.

The pharmacokinetics property of furapromidum $[3,139$, $140]$ is similar to praziquantel. Unfortunately, the very low drug concentration in peripheral blood is not enough to drive the schistosomes distributing in inferior mesenteric veins and its branches to shift to the liver, which results in a lower cure rate obtained by treatment with furapromidum both in rabbits and humans with S. japonicum infection [140-142]. 
The exact action mechanism of praziquantel is still not fully known. Although scientists have made efforts to understand the action of praziquantel on the VGCCs of S. mansoni, opinions remain inconsistent. Praziquantel is less effective in T-cell deprived mice or B-cell depleted mice [86-89]. Meanwhile, a very strong first pass effect of praziquantel through the liver, accompanied by a half-life of a few hours in various animals [143] or $1.5 \mathrm{~h}$ in humans [144] is unfavorable for treatment. But exposure of the worm surface antigen induced by praziquantel triggers the host action of immune effector mechanisms, which plays a synergistic role and results in the death of the worms. Hence, the action mechanism of praziquantel against schistosomes should include the target positions or molecules attacked by the drug, and immune reaction derived from the host. It is thus necessary to conduct in-depth studies on the host action of immune effector mechanisms in the process of killing schistosomes by praziquantel.

Praziquantel was selected from over 400 1,2,3,6,7,11bhexahydro-4H-pyrazino $[2,1-\alpha]$ isoquinolin-4-one and related compounds because of its outstanding anthelmintic properties [143]. The chemical structure of praziquantel has been extensively modified by many scientists, but they have failed to develop a better alternative compound, which has been fully summarized in a recent review [144]. So far, many categories of synthesized compounds have been reported to be effective against schistosomes [7, 145-147]; a few are related to each other, while most are different types. However, the same types of compounds often exhibit very high structural specificities, i.e., modification of an effective compound always obtains the compounds with little effect over the original one. Hence, it is still necessary to design a new category of compounds for the development of new antischistosomal drugs.

\section{Additional file}

Additional file 1: Multilingual abstracts in the five official working languages of the United Nations. (PDF $783 \mathrm{~kb}$ )

\footnotetext{
Abbreviations

AKP: Alkaline phosphatase; AUC: Area under concentration-time course curve; BID: $\beta$ interaction domain; $\mathrm{Ca}^{2+}$ : Calcium ion; $\mathrm{Cmax}$ : Maximum plasma concentration; HBSS: Hanks' balanced salt solution; IFAT: Indirect fluorescent antibody technique; IRS: Immune rabbit serum; $\mathrm{K}^{+}$: Potassium ion; LM: Light microscopy; MEC: Minimal effective concentration; $\mathrm{Mg}^{2+}$ : Magnesium ion; $\mathrm{Na}^{+}$: Sodium ion; NRS: Normal rabbit serum; OZ: Ozonide; PAT: Potassium antimony tartrate; RMP: Resting membrane potential; SEM: Scanning electron microscopy; TEM: Transmission electron microscopy; VGCC: Voltage-gated $\mathrm{Ca}^{2+}$ channel; VOCC: Voltage-operated $\mathrm{Ca}^{2+}$ channel

\section{Funding}

This work was supported by the China International S\&T Cooperation (no: 2014DFA31130).
}

\section{Availability of data and materials}

Data sharing is not applicable to this article as no datasets were generated or analyzed during the current study.

\section{Authors' contributions}

XSH is responsible for designing and writing the review. SJ and CMG critically reviewed, discussed, and modified the paper. All authors read and approved the final paper.

Ethics approval and consent to participate

Not applicable.

\section{Consent for publication}

Not applicable.

\section{Competing interests}

The authors declare that they have no competing interests.

\section{Author details}

${ }^{1}$ National Institute of Parasitic Diseases, Chinese Center for Disease Control and Prevention, Key Laboratory of Parasite and Vector Biology, Ministry of Health, WHO Collaborating Centre for Tropical Diseases, Shanghai 200025, People's Republic of China. Institute for Infectious Disease and Vaccine Development, Tongji University School of Medicine, Shanghai 200092, People's Republic of China.

Received: 25 July 2017 Accepted: 19 January 2018

Published online: 07 February 2018

\section{References}

1. Cox FE. History of human parasitology. Clin Microbiol Rev. 2002;15:595-612.

2. Christopherson JB. Intravenous injections of antimonium tartaratum in Bilharziosis. Br Med J. 1918;2:652-3.

3. Chen MG. Chemotherapy of schistosomiasis japonica in China. Southeast Asian J Trop Med Public Health. 1985;16:473-9.

4. Cioli D, Pica-Mattoccia L, Archer S. Antischistosomal drugs: past, present .. and future? Pharmacol Ther. 1995;68:35-85.

5. Fenwick A, Savioli L, Engels D, Robert Bergquist N, Todd MH. Drugs for the control of parasitic diseases: current status and development in schistosomiasis. Trends Parasitol. 2003;19:509-15.

6. Utzinger J, Keiser J. Schistosomiasis and soil-transmitted helminthiasis: common drugs for treatment and control. Expert Opin Pharmacother. 2004; 5:263-85.

7. Caffrey CR. Chemotherapy of schistosomiasis: present and future. Curr Opin Chem Biol. 2007;11:433-9.

8. Xiao SH, Keiser J, Chen MG, Tanner M, Utzinger J. Research and development of antischistosomal drugs in the People's Republic of China a 60-year review. Adv Parasitol. 2010;73:231-95.

9. Cioli D, Pica-Mattoccia L. Praziquantel. Parasitol Res. 2003;90:S3-9.

10. Chen MG. Use of praziquantel for clinical treatment and morbidity control of schistosomiasis japonica in China: a review of 30 years' experience. Acta Trop. 2005;96:168-76.

11. Black CL, Steinauer ML, Mwinzi PN, Evan Secor W, Karanja DM, Colley DG. Impact of intense, longitudinal retreatment with praziquantel on cure rates of schistosomiasis mansoni in a cohort of occupationally exposed adults in western Kenya. Tropical Med Int Health. 2009;14:450-7.

12. Doenhoff MJ, Cioli D, Utzinger J. Praziquantel: mechanisms of action, resistance and new derivatives for schistosomiasis. Curr Opin Infect Dis. 2008;21:659-67.

13. Mtethiwa AHN, Bakuza J, Nkwengulila G. Prevalence and intensity of schistosomiasis in communities around water reservoirs in Malawi. J Trop Dis. 2015;4:1.

14. World Health Organization. Preventive chemotherapy in human helminthiasis. Coordinated use of anthelminthic drugs in control interventions: a manual for health professionals and programme managers. Geneva: WHO; 2006. p. 235-6.

15. Zhang Y, Koukounari A, Kabatereine N, Fleming F, Kazibwe F, Tukahebwa E, et al. Parasitological impact of 2-year preventive chemotherapy on chistosomiasis and soil-transmitted helminthiasis in Uganda. BMC Med. 2007;5:27

16. Ouedraogo H, Drabo F, Zongo D, Bagayan M, Bamba I, Pima T, et al. Schistosomiasis in school-age children in Burkina Faso after a decade of preventive chemotherapy. Bull World Health Organ. 2016;94:37-45. 
17. Yue WJ, You JQ, Mei JY. Prophylactic activity of praziquantel in animals infected with Schistosoma japonicum. Zhongguo Yao Li Xue Bao. 1985;6: 186-8. (in Chinese)

18. Sabah AA, Fletcher C, Webbe G, Doenhoff MJ. Schistosoma mansoni: chemotherapy of infections of different ages. Exp Parasitol. 1986;61:294-03.

19. Xiao SH, Yue WJ, Yang YQ, You JQ. Susceptibility of Schistosoma japonicum to different developmental stages to praziquantel. Chin Med J. 1987;100:759-68.

20. Pax R, Bennett JL, Fetterer R. A benzodiazepine derivative and praziquantel: effects on musculature of Schistosoma mansoni and Schistosoma japonicum. Naunyn Schmiedeberg's Arch Pharmacol. 1978;304:309-15.

21. Chavasse CJ, Brown MC, Bell DR. Schistosoma mansoni: activity responses in vitro to praziquantel. Z Parasitenkd. 1979;58:169-74.

22. Becker B, Mehlhorn H, Andrews P, Thomas H, Eckert J. Light and electron microscopic studies on the effect of praziquantel on Schistosoma mansoni, Dicrocoelium dendriticum, and Fasciola hepatica (Trematoda) in vitro. Z Parasitenkd. 1980;63:113-28.S.

23. Xiao SH, Shao BR, Yu YG. Preliminary studies on the mode of action of pyquiton against Schistosoma japonicum. Chin Med J. 1984;97:839-48.

24. Xiao SH, Shao BR, Xu YQ, Pan QR. Mode of action of praziquantel on Schistosoma japonicum. Zhongguo Yao Li Xue Bao. 1980;1:51-5. (in Chinese)

25. Xiao SH, Shao BR, Xu YQ. The in vitro effect of pyquiton on Schistosoma japonicum. Acta Pharm Sin. 1980;15:105-8. (in Chinese)

26. Xiao SH, Catto BA, Webster LT Jr. Effects of praziquantel on different developmental stages of Schistosoma mansoni in vitro and in vivo. J Infect Dis. 1985;151:1130-7.

27. Xiao SH, Shao BR, Wang CY, Guo HF, Jiao PY, Ha SH. The effect of pyquiton on the uptake and release of 5-hydroxytryptamine in Schistosoma japonicum. Yao Xue Xue Bao. 1981;16:81-5. (in Chinese)

28. Coles GC. The effect of praziquantel on Schistosoma mansoni. J Helminthol. 1979;53:31-3.

29. Fetterer RH, Pax RA, Bennett JL. Praziquantel, potassium and 2,4dinitrophenol: analysis of their action on the musculature of Schistosoma mansoni. Eur J Pharmacol. 1980;64:31-8.

30. Fetterer RH, Pax RA, Bennett JL. Clonazepam and praziquantel: mode of antischistosomal action. Fed Proc. 1978;37:604

31. Bricker CS, Pax RA, Bennett JL. Microelectrode studies of the tegument and sub-tegumental compartments of male Schistosoma mansoni: anatomical location of sources of electrical potentials. Parasitology. 1982;85:149-61.

32. Bricker CS, Depenbusch JW, Bennett JL, Thompson DP. The relationship between tegumental disruption and muscle contraction in Schistosoma mansoni exposed to various compounds. Z Parasitenkd. 1983;69:61-71.

33. Andrews P. A summary of the efficacy of praziquantel against schistosomes in animal experiments and notes on its mode of action. Arzneimittelforschung. 1981;31:538-41.

34. Xiao SH, Shao BR, Xue YQ, Pan QR. The actions of pyquiton on the morphological changes of schistosomes, oviposition of female worms and hatching of ova. Natl Med J Chin. 1980;60:137-41. (in Chinese)

35. Xiao SH, Shang YC. Studies on the effect of F-30066 on Schistosoma japonicum in vitro. Yao Xue Xue Bao. 1963;10:701-7. (in Chinese)

36. Popiel I, Erasmus DA. Schistosoma mansoni: ultrastructure of adults from mice treated with oxamniquine. Exp Parasitol. 1984;58:254-62.

37. Xiao SH, Catto BA. In vitro and in vivo studies of the effect of artemether on Schistosoma mansoni. Antimicrob Agents Chemother. 1989;33:1557-62.

38. Xiao SH, Xue J, Mei JY, Jiao PY. Effectiveness of synthetic trioxolane OZ78 against Schistosoma japonicum in mice and rabbits. Parasitol Res. 2012;110:2307-14.

39. Xue J, Wang X, Dong Y, Vennerstrom JL, Xiao SH. Effect of ozonide OZ418 against Schistosoma japonicum harbored in mice. Parasitol Res. 2014;113(9):3259-66.

40. You JQ, Mei JY, Xiao SH. Effect of artemether against Schistosoma japonicum. Zhongguo Yao Li Xue Bao. 1992;13:280-4. (in Chinese)

41. You JQ, Xiao SH, Yue WJ. Effect of praziquantel in vitro on different developmental stages of Schistosoma japonicum. Zhongguo Yao Li Xue Bao. 1986;7:82-4. (in Chinese)

42. Xiao SH, You JQ, Zhang RQ. Scanning electron microscope observation on the tegumental surface alterations of Schistosoma japonicum induced by praziquantel at different developmental stages. Yao Xue Xue Bao. 1985;20: 577-83. (in Chinese)

43. Andrews P. Praziquantel: mechanisms of anti-schistosomal activity. Pharmacol Therapeut. 1985;29:129-56.

44. Yang $\mathrm{YQ}$, Yang $\mathrm{HZ}$, Xiao $\mathrm{SH}$. Effects of praziquantel on the tegument of different developmental stages of Schistosoma japonicum and host cell response. Zhongguo Ji Sheng Chong Xue Yu Ji Sheng Chong Bing Za Zhi. 1987:5:207-9, 11. (in Chinese)

45. Yang $Y Q$, Yang $H Z$, Zhang CW. Effect of pyquition on some histochemical activities of schistosomules of Schistosoma japonicum in mice. Ji Sheng Chong Xue Yu Ji Sheng Chong Bing Za Zhi. 1986;4:21-4. (in Chinese)

46. You JQ, May JY, Xiao SH. Observation on effect of praziquantel combined with artesunate on mouse schistosomiasis. Chin J Parasitic Dis Contr. 1994;7: 50-1. (in Chinese)

47. Xiao SH, Shen BG. Scanning electron microscope observation on tegumental damage of 21-d-old Schistosoma japonicum induced by praziquantel. Zhongguo Yao Li Xue Bao. 1995;16:273-5. (in Chinese)

48. Mehlhorn H, Kojima S, Rim HJ, Ruenwongsa P, Andrews P, Thomas H, Bunnag B. Ultrastructural investigations on the effects of praziquantel on human trematodes from Asia: Clonorchis sinensis, Metagonimus yokogawai, Opisthorchis viverrini, Paragonimus westermani and Schistosoma japonicum. Arzneimittelforschung. 1983;33:91-8.

49. Xiao SH, Yang YQ, Shu YS, Wang Z. Ultrastructural changes of the tegument, syncithium, vitelline cells and muscles of Schistosoma japonicum caused by pyquiton. Acta Zool Sin. 1981;27:305-9. (in Chinese)

50. Xiao SH, Dai ZJ, Zhang RQ, Xue HC, Shao BR. Scanning electron microscope observations on tegumental surface alterations of Schistosoma japonicum induced by pyquiton. Yao Xue Xue Bao. 1982;17:498-502. (in Chinese)

51. Yang SJ, Li W, Su XS. Scanning electron microscopy of the effect of pyquiton on the tegument of Schistosoma japonicum. Ji Sheng Chong Xue Yu Ji Sheng Chong Bing Za Zhi. 1985;3:178-80. (in Chinese)

52. Lian WN, Huang MY, Wei CZ, Xu ZY, Xu ML. Scanning electron microscopic observation on tegumental damage of Schistosoma japonicum treated with lower dose praziquantel. Chin J Schisto Contr. 1989;4:12-3. (in Chinese)

53. Smithers SR. Immunity to schistosomiasis. Proc R Soc Med. 1973;66:778-9.

54. Xiao SH, Xue HC, Guo HF, Yang HZ, Shao BR. The appearance of surface antigen of Schistosoma japonicum recovered from infected mice after the treatment with pyquiton. Shanghai J Immunol. 1981;1:9-15. (in Chinese)

55. Yue WJ, Mei JY, Xiao SH. Effects of praziquantel and artemether on tegumental surface antigens of different developmental stages of Schistosoma japonicum. Ji Sheng Chong Xue Yu Ji Sheng Chong Bing Za Zhi. 1986;4:284-7. (in Chinese)

56. Xiao SH, Fu S, Ba C. Recent laboratory investigations by Chinese workers on antischistosomal activities of praziquantel. Chin Med J. 1991;104:599-606.

57. Xiao SH, You JQ, Guo HF, Catto BA. Uptake and effect of praziquantel and the major human oxidative metabolite, 4-hydroxypraziquantel, by Schistosoma japonicum. J Parasitol. 1991;77:241-5.

58. Xiao SH, Yu YG, Wang CY, Jiao PY, Yuan XJ, Liang YY. The uptake and distribution of 3H-pyquiton in Schistosoma japonicum. Acta Pharm Sin. 1981 16:488-93. (in Chinese)

59. Xiao SH, Yang YQ, Yang HZ, Yu YG. Distribution of $3 \mathrm{H}$-praziquantel in tissues of Schistosoma japonicum at different developmental stages. Acta Pharm Sin. 1986;21:377-81. (in Chinese)

60. Wang MN, Liu YH, Lu XE, Sun YS. In vitro effect on Schistosoma japonicum by pyquiton produced in China. J Chongqing Med Univ. 1980;1:64-7. (in Chinese)

61. Wolde Mussie E, Vande Waa J, Pax RA, Fetterer R, Bennett JL. Schistosoma mansoni: calcium efflux and effects of calcium-free media on responses of the adult male musculature to praziquantel and other agents inducing contraction. Exp Parasitol. 1982;53:270-8.

62. Wolde Mussie E, Bennett JL. Plasma spectrometric analysis for $\mathrm{Na}, \mathrm{K}, \mathrm{Ca}, \mathrm{Mg}$, Fe and Cu in Schistosoma mansoni and S.japonicum. J Parasitol. 1982;68:48-52.

63. Xiao SH, Friedman PA, Catto BA, Webster LT Jr. Praziquantel-induced vesicle formation in the tegument of male Schistosoma mansoni is calcium dependent. J Parasitol. 1984;70:177-9.

64. Xiao SH, Sun HL, Jiao PY. Effect of pyquiton on calcium uptake of the male Schistosoma japonicum under various conditions. Acta Pharm Sin. 1984;19: 727-31. (in Chinese)

65. Xiao SH, Guo HF, Dai ZQ, Zhang RQ. Effect of calcium, magnesium and temperature on praziquantel-induced tegument damage of the male Schistosoma japonicum. Zhongguo Yao Li Xue Bao. 1985;6:59-63. (in Chinese)

66. Xiao SH, Zhu SS, Sun HL, Jiao PY, Yao MY. Effect of praziquantel on $\mathrm{Ca}^{2+}$, $\mathrm{Mg}^{2+}, \mathrm{K}^{+}$and $\mathrm{Na}^{+}$content and distribution of ${ }^{45} \mathrm{Ca}^{2+}$ in male Schistosoma japonicum. Acta Pharm Sin. 1985;20:815-20. (in Chinese)

67. Kohn AB, Anderson PA, Roberts-Misterly JM, Greenberg RM. Schistosome calcium channel beta subunits. Unusual modulatory effects and potential role in the action of the antischistosomal drug praziquantel. J Biol Chem. 2001;276:36873-6. 
68. Kohn AB, Lea J, Roberts-Misterly JM, Anderson PA, Greenberg RM. Structure of three high voltage-activated calcium channel alpha1 subunits from Schistosoma mansoni. Parasitology. 2001;123:489-97.

69. Kohn AB, Roberts-Misterly JM, Anderson PA, Greenberg RM. Creation by mutagenesis of a mammalian $\mathrm{Ca}(2+)$ channel beta subunit that confers praziquantel sensitivity to a mammalian $\mathrm{Ca}(2+)$ channel. Int J Parasitol. 2003; 33:1303-8.

70. Kohn AB, Roberts-Misterly JM, Anderson PA, Khan N, Greenberg RM. Specific sites in the Beta interaction domain of a schistosome $\mathrm{Ca}^{2+}$ channel beta subunit are key to its role in sensitivity to the anti-schistosomal drug praziquantel. Parasitology. 2003;127:349-56.

71. Greenberg RM. Are $\mathrm{Ca}^{2+}$ channels targets of praziquantel action? Int J Parasitol. 2005;35:1-9.

72. Mendonca-Silva DL, Novozhilova E, Cobbett PJ, Silva CL, Noel F, Totten Ml, Maule AG, Day TA. Role of calcium influx through voltage-operated calcium channels and of calcium mobilization in the physiology of Schistosoma mansoni muscle contractions. Parasitology. 2006;133:67-74.

73. Angelucci F, Basso A, Bellelli A, Brunori M, Pica Mattoccia L, Valle C. The antischistosomal drug praziquantel is an adenosine antagonist. Parasitology. 2007;134:1215-21.

74. Valle C, Troiani AR, Festucci A, Pica-Mattoccia L, Liberti P, Wolstenholme A, et al. Sequence and level of endogenous expression of calcium channel beta subunits in Schistosoma mansoni displaying different susceptibilities to praziquantel. Mol Biochem Parasitol. 2003;130:111-5.

75. Aragon AD, Imani RA, Blackburn VR, Cupit PM, Melman SD, Goronga T, et al. Towards an understanding of the mechanism of action of praziquantel. Mol Biochem Parasitol. 2009;164:57-65.

76. Nogi T, Zhang D, Chan JD, Marchant JS. A novel biological activity of praziquantel requiring voltage-operated $\mathrm{Ca}^{2+}$ channel beta subunits: subversion of flatworm regenerative polarity. PLoS Negl Trop Dis. 2009;3:e464.

77. Pica-Mattoccia L, Valle C, Basso A, Troiani AR, Vigorosi F, Liberti P, et al. Cytochalasin D abolishes the schistosomicidal activity of praziquantel. Exp Parasitol. 2007;115:344-51.

78. Cai R, Li X, Zhang HQ, Gong W, Luo W, Xia CM. Effect of calcium channel blockers and actin depolymerizing/stabilizing agents on the survival of Schistosoma japonicum treated with praziquantel in vitro. Chin J Zoonoses. 2009;25:1186-91. (in Chinese)

79. Cai R, Yang QL, Zhang HQ, Xia CM. Effect of Cytochalasin D and calcium channel blockers on ultrastructure of Schistosoma japonicum treated with praziquantel in vitro. Chin J Zoonoses. 2010;26:315-9. (in Chinese)

80. Pica-Mattoccia L, Orsini T, Basso A, Festucci A, Liberti P, Guidi A, et al. Schistosoma mansoni: lack of correlation between praziquantel-induced intra-worm calcium influx and parasite death. Exp Parasitol. 2008;119:332-5.

81. Silva-Moraes V, Couto FF, Vasconcelos MM, Araujo N, Coelho PM, Katz N, et al. Antischistosomal activity of a calcium channel antagonist on schistosomula and adult Schistosoma mansoni worms. Mem Inst Oswaldo Cruz. 2013;108:600-4.

82. Xiao SH, Shao BR, Guo HF, Xu YQ, Wang CY, Jiao PY, Ha SH. Absorption, distribution and excretion of the schistosomicide, pyquiton, in rabbits using biological assay. Acta Pharm Sin. 1980;15:135-41. (in Chinese)

83. Xiao SH, You JQ, Guo HF, Yang B. Relationship between the efficacy and plasma concentration of praziquantel in mice and rabbits infected with Schistosoma japonicum. Chin J Pharmacol Toxicol. 1987;1:287-92. (in Chinese)

84. Xiao SH, You JQ, Guo HF, Catto BA. Plasma pharmacokinetics and therapeutic efficacy of praziquantel and 4-hydroxypraziquantel in Schistosoma japonicum-infected rabbits after oral, rectal, and intramuscular administration. Am J Trop Med Hyg. 1992;46:582-8.

85. El-Feky GS, Mohamed WS, Nasr HE, El-Lakkany NM, Seif El-Din SH, Botros SS. Praziquantel in a clay nanoformulation shows more bioavailability and higher efficacy against murine Schistosoma mansoni infection. Antimicrob Agents Chemother. 2015;59:3501-8.

86. Sabah AA, Fletcher C, Webbe G, Doenhoff MJ. Schistosoma mansoni: reduced efficacy of chemotherapy in infected T-cell-deprived mice. Exp Parasitol. 1985;60:348-54

87. Brindley PJ, Sher A. The chemotherapeutic effect of praziquantel against Schistosoma mansoni is dependent on host antibody response. J Immunol. 1987;139:215-20.

88. Doenhoff MJ, Modha J, Lambertucci JR. Anti-schistosome chemotherapy enhanced by antibodies specific for a parasite esterase. Immunology. 1988; 65:507-10.
89. Doenhoff MJ. The immune-dependence of chemotherapy in experimental schistosomiasis. Mem Inst Oswaldo Cruz. 1989;84:31-7.

90. Xiao SH, Guo HF, Zhang RQ, Xue HC, Qiu LS. Effect of immune serum on the male Schistosoma japonicum subjected to pyquiton. Yao Xue Xue Bao. 1985;20:10-6. (in Chinese)

91. Xiao SH, Guo HF, Xue HC, Qiu LS, Zhang RQ. Attachment of mouse neutrophils in vitro on the praziquantel-damaged surface of adult Schistosoma japonicum in the presence of immune sera. Zhongguo Yao Li Xue Bao. 1986;7:165-70. (in Chinese)

92. Xiao SH, Guo HF, You JQ, Qiu LZ. Influence of praziquantel on neutrophil chemotactic activity induced by Schistosoma japonicum. Shanghai J Immunol. 1987;6:286-7. (in Chinese)

93. Xiao SH, Yang YQ, Yang HZ, Guo HF, Shao BR. Observation on tegument damage of Schistosoma japonicum and penetration of host leukocytes into the worm body caused by pyquiton. Yao Xue Xue Bao. 1983;18:241-6. (in Chinese)

94. Andrews $\mathrm{P}$, Thomas $\mathrm{H}$, Weber $\mathrm{H}$. The in vitro uptake of ${ }^{14} \mathrm{C}$-praziquantel by cestodes, trematodes, and a nematode. J Parasitol. 1980;66:920-5.

95. Xiao SH, Qiu LS, Wu GZ, Yue WJ, Xue HC, You JQ, et al. Relationship between the efficacy of praziquantel on rabbits infected with Schistosoma japonicum and the immune level of the host. Yao Xue Xue Bao. 1986;21: 725-30. (in Chinese)

96. Yue WJ, Xiao SH, Mei JY. Relationship between the effects of praziquantel on mice and rabbits with different intensities of Schistosoma japonicum infection and humoral immunity levels of the host. Zhongguo Yao Li Xue Bao. 1989;10:476-9. (in Chinese)

97. Xiao SH, Yue WJ, Mei JY. Susceptibility of schistosomula at various ages to praziquantel during invasion in mouse skin and observations on certain characteristics of the schistosomula surface. Zhongguo Yao Li Xue Bao. 1987;8:261-6. (in Chinese)

98. Xiao SH, Yue WJ, Mei JY. Effects of praziquantel in vitro on adherence of neutrophils to schistosomula and killing of the worms. Zhongguo Yao Li Xue Bao. 1987:8:547-51. (in Chinese)

99. Xiao SH, Wu GZ, Xue HC, Guo HF, Song GC, Qiu LS. Effect of praziquantel on mice immunity in the early stage after infection with Schistosoma japonicum cercariae. Acta Pharmacol Sin. 1987;8:60-3. (in Chinese)

100. Ye P, Shi FH, Tian E, Shi YJ, Lin BF, Zhu SH. Class lgG1 monoclonal antibodiesand praziquantel synergetically preventing the infectin of Schistosoma japonicum. Chin J Vet Parasitol. 1993;1:32-5. (in Chinese)

101. Ye P, Tian E, Li JJ, Shi YJ, Lin BF, Zhu SH, Shi FH. Studies on monoclonal antibodies and praziquantel synergically killing Schistosoma japonicum. Chin J Parasit Dis Contr. 1994;7:183-5. (in Chinese)

102. Ye P, Tian E, Lin JJ, Shi YJ, Zhu SH, Lin BF, Shi FH. Preliminary studies on the synergestic effect of monoclonal antibody and drugs in killing adult worms of Schistosoma japonicum. Chin J Schisto Control. 1994;6:327-30. (in Chinese)

103. Shen JJ, Jiang ZZ, Wang XL, Wang W, Jiang BL. Effect of monoclonal antibody against schistosomula membrane and praziquantel synergically killing Schistosoma japonicum. Chin Pharmacol Bull. 1998;14:440-2. (in Chinese)

104. Zhang ZP, Zeng QR, Wu X, Zhang SK, Chen J, Huang ZH, et al. Effect of monoclonal antibodies against surface membrane antigen of adult Schistosoma japonicum on the schistosomicidal role of praziquantel. Bull Hunan Med Univ. 2003;28:455-8. (in Chinese)

105. Zhang ZP, Zeng QR, Gong YF, Yan GW, Shen J. Experimental study on synergic effect of immune serum against surface membrane antigen of Schistosoma japonicum adult and praziquantel in killing different developmental stage of worms. Chin J Parasit Dis Contr. 2005;18:48-5. (in Chinese)

106. Wu GZ, Liu SX, Xiao SH. Effects of praziquantel on the immunological response in mice infected with Schistosoma japonicum. Zhongguo Yao Li Xue Bao. 1988;9:163-6. (in Chinese)

107. Xiao SH, Yue WJ, Mei JY. Analysis of the prophylactic effect of praziquantel on mice infected with Schistosoma japonicum cercariae. Yao Xue Xue Bao. 1985;20:641-6. (in Chinese)

108. Xiao SH, Yue WJ, Mei JY, Zhang RQ. Effect of praziquantel on Schistosoma japonicum cercariae. Zhongguo Yao Li Xue Bao. 1987;8:358-62. (in Chinese)

109. Xiao SH, Yang YQ, Shen BG, Xu DH, Yang HZ, Mei JY, Yue WJ. Effect of praziquantel on ultrastructure of Schistosoma japonicum cercariae and schistosomula within mouse skin. Zhongguo Yao Li Xue Bao. 1988;9(4):3603. (in Chinese)

110. Yang YQ, Yang HZ, Zhang CW. Histological observation on the effects of praziquantel on schistosomulae of Schistosoma japonicum in mouse skin. Zhongguo Yao Li Xue Bao. 1984;5:63-6. (in Chinese) 
111. Xiao SH, You JQ, Mei JY, Jiao PY. Early treatment of schistosomal infection with praziquantel in mice. Zhongguo Yao Li Xue Bao. 1993;14:533-8.

112. Xiao S, You J, Mei J, Jiao P, Guo H, Feng J, et al. Early treatment with artemether and praziquantel in rabbits repeatedly infected with Schistosoma japonicum cercariae. Zhongguo Ji Sheng Chong Xue Yu Ji Sheng Chong Bing Za Zhi. 1994;12:252-6. (in Chinese)

113. Xiao SH, Yang YQ, Zhang CW, You JQ. Microscopic observations on livers of rabbits and dogs infected with Schistosoma japonicum cercariae and early treatment with artemether or praziquantel. Zhongguo Yao Li Xue Bao. 1996; 17:167-70

114. Fallon PG, Doenhoff MJ. Drug-resistant schistosomiasis: resistance to praziquantel and oxamniquine induced in Schistosoma mansoni in mice is drug specific. Am J Trop Med Hyg. 1994;51:83-8.

115. Stelma FF, Talla I, Sow S, Kongs A, Niang M, Polman K, et al. Efficacy and side effects of praziquantel in an epidemic focus of Schistosoma mansoni. Am J Trop Med Hyg. 1995;53:167-70.

116. Fallon PG, Sturrock RF, Niang AC, Doenhoff MJ. Short report: diminished susceptibility to praziquantel in a Senegal isolate of Schistosoma mansoni. Am J Trop Med Hyg. 1995;53:61-2.

117. Ismail M, Botros S, Metwally A, William S, Farghally A, Tao LF, et al. Resistance to praziquantel: direct evidence from Schistosoma mansoni isolated from Egyptian villagers. Am J Trop Med Hyg. 1999;60:932-5.

118. William S, Botros S, Ismail M, Farghally A, Day TA, Bennett JL. Praziquantelinduced tegumental damage in vitro is diminished in schistosomes derived from praziquantel-resistant infections. Parasitology. 2001;122:63-6.

119. Danso-Appiah A, De Vlas SJ. Interpreting low praziquantel cure rates of Schistosoma mansoni infections in Senegal. Trends Parasitol. 2002;18:125-9.

120. Gryseels B, Mbaye A, De Vlas SJ, Stelma FF, Guisse F, Van Lieshout L, et al. Are poor responses to praziquantel for the treatment of Schistosoma mansoni infections in Senegal due to resistance? An overview of the evidence. Tropical Med Int Health. 2001;6:864-73.

121. William S, Sabra A, Ramzy F, Mousa M, Demerdash Z, Bennett JL, et al, Stability and reproductive fitness of Schistosoma mansoni isolates with decreased sensitivity to praziquantel. Int J Parasitol. 2001;31:1093-100.

122. Botros SS, Bennett JL. Praziquantel resistance. Expert Opin Drug Discov. 2007:2:S35-40.

123. Melman SD, Steinauer ML, Cunningham C, Kubatko LS, Mwangi IN, Wynn $N B$, et al. Reduced susceptibility to praziquantel among naturally occurring Kenyan isolates of Schistosoma mansoni. PLoS Negl Trop Dis. 2009;3:e504.

124. Cioli D. Praziquantel: is there real resistance and are there alternatives? Curr Opin Infect Dis. 2000;13:659-63.

125. Yue WJ, Yu SH, Xu XJ. Failure to induce resistance of Schistosoma japonicum to praziquantel. Southeast Asian J Trop Med Public Health. 1990;21:85-9.

126. Yue WJ, Xue XJ. Mei. Experimental studies on the resistance of Schistosoma japonicum to praziquantel. Chin J Schistos Contr. 1991;3:195-8. (in Chinese)

127. Li HJ, Liang YS, Dai JR, Wang W, Qu GL, Li YZ, et al. Studies on resistance of Schistosoma to praziquantel XIV experimental comparison of susceptibility to praziquantel between PZQ-resistant isolates and PZQ-susceptible isolates of Schistosoma japonicum in stages of adult worms, miracidia and cercariae. Zhongguo Xue Xi Chong Bing Fang Zhi Za Zhi. 2011;23:611-9. (in Chinese)

128. Liang YS, Li HJ, Dai JR, Wang W, Qu GL, Tao YH, et al. Studies on resistance of Schistosoma to praziquantel XIII resistance of Schistosoma japonicum to praziquantel is experimentally induced in laboratory. Zhongguo Xue Xi Chong Bing Fang Zhi Za Zhi. 2011;23:605-10. (in Chinese)

129. Wang W, Li HJ, Liang YS, Qu GL, Li YZ, Xing YT, et al. Studies on resistance of Schistosoma to praziquantel XIIV sensitivity of Schistosoma japonicum to praziquantel in marshland and lake endemic regions of Chinese Mainland. Zhongguo Xue Xi Chong Bing Fang Zhi Za Zhi. 2012;24:505-9. (in Chinese)

130. Liang YS, Dai JR, Ning A, Yu DB, Xu XJ, Zhu YC, et al. Susceptibility of Schistosoma japonicum to praziquantel in China. Tropical Med Int Health. 2001;6:707-14

131. Wang W, Dai JR, Li HJ, Shen XH, Liang YS. The sensitivity of Schistosoma japonicum to praziquantel: a field evaluation in areas with low endemicity of China. Am J Trop Med Hyg. 2012;86:834-6.

132. Wang W, Dai JR, Li HJ, Shen XH, Liang YS. Is there reduced susceptibility to praziquantel in Schistosoma japonicum? Evidence from China. Parasitology. 2010;137:1905-12.

133. Yu DB, Li Y, Sleigh AC, Yu XL, Li YS, Wei WY, et al. Efficacy of praziquantel against Schistosoma japonicum: field evaluation in an area with repeated chemotherapy compared with a newly identified endemic focus in Hunan China. Trans R Soc Trop Med Hyg. 2001;95:537-41.
134. Hang PY, Liang YS, Dai JR, Zhu YC, Ning A, Yu DB, et al. Study on susceptibility of Schistosoma japonicum in different stages to praziquantel. Chin J Schisto Contr. 2011;13:343-6. (in Chinese)

135. Liang YS, Dai JR, Zhu YC, Hang PY, Li HJ, Zhao S, et al. Studies on resistance of Schistosoma japonicun to praziquantel $X$. Field investigation on susceptibility of Schistosoma japonicum in China. Chin J Schisto Contr. 2005; 17:328-32. (in Chinese)

136. Shi MZ, Yu DB, Wei WY, Zhang CS, He HB, Yang GF, et al. Experimental study on susceptibility of praziquantel against Schistosoma japonicum in repeated chemotherapy areas in Dongting Lake region. Chin J Schisto Contr. 2004;16:171-3. (in Chinese)

137. Song HT, Liang YS, Dai JR, Li LG, Shen XH, Tian QA, et al. Studies on sensitivity of Schistosoma japonicum to praziquantel situation in low endemic areas. Chin J Schisto Contr. 2004;16:58-9. (in Chinese)

138. Botros S, Sayed H, Amer N, El-Ghannam M, Bennett JL, Day TA. Current status of sensitivity to praziquantel in a focus of potential drug resistance in Egypt. Int J Parasitol. 2005;35:787-91.

139. Huang TY, Wang KF, Yu TC. Observations on the fate of F30066-a new schistosomicide-in man and in laboratory animals. Chin Med J. 1963;82: 242-9. (in Chinese)

140. Liu X, Lu SZ. A review on furapromidum in pharmacology and clinical trial. Chin J Intern Med. 1965;13:568-71. (in Chinese)

141. Hsiao SH, Liu JC, Chan CC. Combined oral F30066 and rectal dipterex in treatment of experimental schistosomiasis japonica. Chin Med J. 1975;1:51-9.

142. Hsu JK, Lu CP, Yang CC, Lu CS, Chiang HJ. Preliminary trials with F30066 and F30069 in Schistosoma japonicum infections in man. Chin Med J. 1963;82:92-6.

143. Andrews P, Thomas H, Pohlke R, Seubert J. Praziquantel. Med Res. 1983;3: 147-200.

144. da Silva VBR, Campos B, de Oliveira JF, Decout JL, do Carmo Alves de Lima M. Medicinal chemistry of antischistosomal drugs: Praziquantel and oxamniquine. Bioorgan Med Chem. 2017;25:3259-77.

145. Cioli D, Pica-Mattoccia L, Basso A, Guidi A. Schistosomiasis control: praziquantel forever? Mol Biochem Parasit. 2014;195:23-9.

146. Cioli D, Valle C, Angelucci F, Miele AE. Will new antischistosomal drugs finally emerge? Trends Parasitol. 2008;24:379-82.

147. Xiao SH. Progress in development of new antischistosomal drugs in recent years. Zhongguo Ji Sheng Chong Xue Yu Ji Sheng Chong Bing Za Zhi. 2010;28:218-25. (in Chinese)

\section{Submit your next manuscript to BioMed Central and we will help you at every step:}

- We accept pre-submission inquiries

- Our selector tool helps you to find the most relevant journal

- We provide round the clock customer support

- Convenient online submission

- Thorough peer review

- Inclusion in PubMed and all major indexing services

- Maximum visibility for your research

Submit your manuscript at www.biomedcentral.com/submit
) Biomed Central 